\title{
Identifikasi Kerentanan Longsor Daerah Pangalengan Dengan Metode Slope Morphology
}

\begin{tabular}{l}
\hline Received \\
23 Maret 2017 \\
Revised \\
30 Mei 2017 \\
Accepted for Publication \\
30 Mei 2017 \\
Published \\
30 Juli 2017 \\
\hline
\end{tabular}

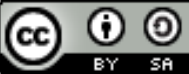

This work is licensed under a Creative ShareAlike 4.0 nternation

\author{
R Amukti*, D Mildan, I A Dinata, N F Isniarno, I K Wijaksana \\ Jurusan Teknik Pertambangan, Fakultas Teknik, Universitas Islam Bandung, Jl. Taman Sari No. 1, \\ Bandung, 40116, Indonesia \\ *E-mail: rian.amukti@unisba.ac.id, rian.amukti87@gmail.com
}

\begin{abstract}
Pangalengan is located between $107^{\circ} 29^{\prime}-107^{\circ} 39$ 'BT and $7^{\circ} 19^{\prime}-7^{\circ} 6^{\prime}$ LS. Based on its topography and geological condition, Pangalengan has steep slopes and lies between two strike-slip faults. Average annual rainfall of this area is about $1,996 \mathrm{~mm}$ with $5.47 \mathrm{~mm}$ of average daily rainfall. The area is about 27294.79 hectares with population of 148353 inhabitants. According to these data, Pangalengan has high risk of landslide. Landslide occurred in Pangalengan on 05-05-2015 at 14:00 pm, caused 9 fatalities, 4 people seriously injured, 134 people evacuated, 10 houses buried, geothermal steam flow pipe of Energy Star damaged. It is necessary to analyze slope morphology and study the potential hazard areas of landslide. The result shows that Cibitung which has steep (35o-45o) and very steep $\left(45^{\circ}-65^{\circ}\right)$ slope is prone to landslide with an area of \pm 3038 hectares spread to the south.
\end{abstract}

Keywords: Landslides, geology, rainfall, slope morphology.

\begin{abstract}
Abstrak
Kecamatan Pangalengan terletak pada $107^{\circ} 29^{\prime}-107^{\circ} 39^{\prime}$ BT dan $7^{\circ} 19^{\prime}-7^{\circ} 6^{\prime}$ LS. Ditinjau dari topografi dan geologinya, maka daerah memiliki kelerengan yang curam dan diapit oleh dua sesar geser. Secara iklim Pangalengan memiliki curah hujan sebanyak 1.996 $\mathrm{mm} /$ tahun dengan rata-rata 5,47 mm/perhari. Jumlah penduduk di Kecamatan Pangalengan sebesar 148.353 jiwa dengan luas wilayah sebesar 27.294,79 ha. Berdasarkan data-data tersebut maka daerah Pangalengan memiliki resiko yang besar untuk terjadi bencana longsor. Bencana tanah longsor pernah terjadi di Pangalengan. pada tanggal 05-05-2015, pukul 14.00 WIB menyebabkan korban jiwa 9 orang meninggal, 4 orang luka berat, sebanyak 134 orang mengungsi, 10 rumah tertimbun dan terputusnya pipa aliran uap panas bumi Star Energi. Untuk menanggulangi hal itu, maka diperlukan analisis slope morphology dan studi wilayah yang berpotensi terjadinya bahaya longsor. Hasil analisis slope morphology memperlihatkan bahwa daerah yang sangat rawan terjadi longsor adalah daerah Cibitung dengan analisis kemiringan lereng memiliki slope terjal $\left(35^{\circ}-45^{\circ}\right)$ dan sangat terjal $\left(45^{\circ}-65^{\circ}\right)$ dengan luas area \pm 3.038 ha menyebar ke arah selatan.
\end{abstract}

Kata Kunci: longsor, geologi, curah hujan, slope morphology.

\section{Pendahuluan}

Tanah longsor merupakan salah satu gejala bencana alam dari gerakan massa tanah atau batuan yang menuruni lereng. Tanah longsor disebabkan oleh gangguan kesetabilan tanah atau batuan penyusun lereng tersebut. Bencana longsor sering terjadi di Indonesia dengan faktor utama adalah curah hujan yang cukup tinggi karena Indonesia merupakan negara dengan iklim tropis.

Kecamatan Pangalengan terletak pada $107^{\circ} 29^{\prime}-107^{\circ} 39^{\prime}$ Bujur Timur dan $7^{\circ} 19^{\prime}-7^{\circ} 6^{\prime}$ Lintang Selatan. Pada tahun 2015 bencana tanah longsor pernah terjadi di Pangalengan. Badan Nasional Penanggulangan Bencana (BNPB) menyebutkan bahwa pada tanggal 5 Mei 2015, pukul 14.00 WIB terjadi bencana tanah longsor di Kecamatan Pengalengan, Kabupaten Bandung, Jawa Barat. Panjang longsoran $1 \mathrm{Km}$ dengan lebar $500 \mathrm{~m}$. Longsoran menyebabkan meledaknya pipa gas milik PT. Geothermal Star Energy. Korban jiwa dinyatakan 9 orang meninggal, yang ditemukan 7 orang, 4 
orang luka berat, sebanyak 134 orang mengungsi, 10 rumah tertimbun dan terputusnya pipa aliran uap panas bumi Star Energi antara kampung Cibitung dan Separator Aera [1].

Berdasarkan fakta tersebut, maka upaya pengurangan resiko bencana tanah longsor sangat perlu dilakukan. Upaya untuk mendukung hal tersebut adalah dengan melakukan penelitian identifikasi kerentanan longsor daerah Pangalengan dengan metode slope morphology yang dapat dijadikan landasan awal untuk kegiatan mitigasi bencana selanjutnya.

Daerah penelitian adalah Desa Margamukti Kecamatan Pangalengan terletak secara administratif termasuk wilayah Kabupaten Bandung. Desa Margamukti berbatasan dengan desa-desa lain (Gambar 1). Desa-desa yang berbatasan di sebelah utara dengan Desa Margamukti adalah Desa Pangalengan dan Desa Margamulya, sedangkan di sebelah selatan berbatasan dengan Desa Sukamanah dan Desa Manasuka. Semenetara itu di sebelah barat Desa Mergamukti berbatasan dengan Desa Margamekar, dan sebelah timur berbatasan dengan Desa Girimulya, Desa Cibeureum, dan Desa Tarumajaya.

\section{Metode Penelitian}

Data yang digunakan dalam penelitian ini adalah Digital Elevation Model (DEM) yang didapatkan dari Aster Global DEM. Data DEM ini diproyeksi menjadi sistem koordinat UTM (Universal Travers Mercator) Zone $48 \mathrm{~S}$ dalam satuan meter (m), sehingga dapat dicari luasan daerah yang terindikasi rawan longsor. Metode yang digunakan untuk analisis rawan longsor ini adalah slope morphology [2]. Pada penelitian Shaw dan Jonhson membuat matrik idetifikasi dengan cara menggabungkan antara sudut kelerengan (dalam satuan \%) dan bentuk lereng (cekung, cembung dan datar).

Metode slope morphology ini adalah perhitungan sudut kemiringan lereng yang dibentuk antara bidang permukaan tanah dengan bidang normal. Perhitungan sudut kemiringan lereng pada penelitian ini digunakan dalam satuan derajat. Persamaan sederhana untuk mencari klasifikasi slope morphology kemiringan lereng tersebut adalah dengan dua cara yaitu,

$$
\begin{aligned}
& a=\tan ^{-1}\left(\frac{b}{c}\right) \\
& a=\frac{b}{c} \times 100 \%
\end{aligned}
$$

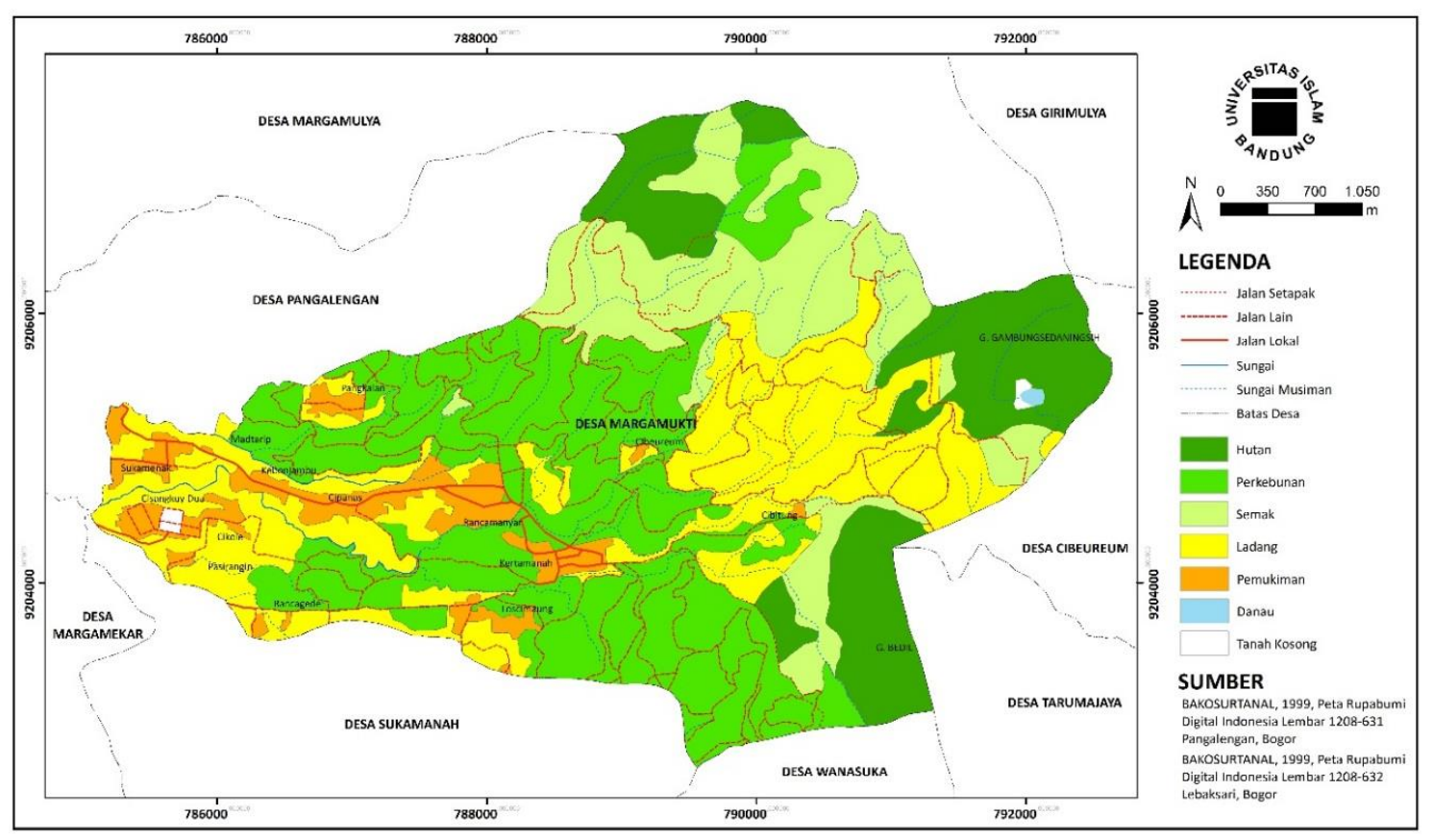

Gambar 1. Peta Administrasi Desa Margamukti, Kecamatan Pangalengan, Kabupaten Bandung [3]. 
dengan $a$ adalah slope/kemiringan lereng, $b$ adalah beda tinggi dan $c$ adalah jarak. Persamaan yang digunakan untuk mencari slope morphology pada penelitian ini adalah dengan satuan derajat. Kemiringan lereng pada metode ini dibagi menjadi beberapa klasifikasi yaitu sangat terjal $\left(>45^{\circ}\right)$, terjal $\left(35^{\circ}-45^{\circ}\right)$, sedang $\left(25^{\circ}-35^{\circ}\right)$, landai $\left(16^{\circ}-25^{\circ}\right)$, dan sangat landai $\left(\leq 15^{\circ}\right)$. Kemiringan yang sangat terjal dan terjal mengindikasikan daerah tersebut memiliki kerentanan terhadap bencana longsor. Metode slope morphology ini telah banyak digunakan untuk mengidentifikasi kerawanan longsor seperti contohnya slope morphology model derived from digital elevation data [2], penelitian tentang identifikasi daerah rawan longsor menggunakan metode SMORPH-slope morphology di Kota Manado [4], dan analisis daerah rawan longsor berbasis sistem informasi geografis kabupaten lima puluh kota, Sumatera Barat [5].

\section{Hasil dan Pembahasan}

Analisis geologi regional dilakukan pada daerah penelitian untuk mendapatkan informasi awal tentang litologi dan struktur yang ada. Secara geologi daerah Pangalengan terdiri dari batuan gunungapi Malabar-Tilu Tuf dan breksi lahar, endapan rempah lepas gunungapi tua tak teruraikan tuf hablur halus kasar dasitan Breksi tuffan yang mengandung batu apung dan endapan lahar tua bersifat andesit basalan, dan Andesit waringin bedil Malabar Tua: persilangan lava breksi dan tuf bersusunan Andesit Piroksen dan Hornblend [6]. Berdasarkan topografinya sebagian besar wilayah merupakan pegunungan atau perbukitan dengan ketinggian di atas permukaan laut $984-1.571 \mathrm{~m}$.

Kecamatan Pangalengan ini jika ditinjau dari topografi dan geologinya, maka memiliki potensi cukup besar untuk terjadi bencana longsor karena memiliki kontur yang curam dan diapit oleh dua sesar geser (Gambar 2). Secara iklim pun daerah ini sangat berpotensi untuk terjadi longsor karena curah hujan diketahui secara umum adalah penyebab utama terjadinya bencana longsor. Curah hujan pada tahun 2016 sebanyak $1.996 \mathrm{~mm} /$ tahun dengan rata-rata $5,47 \mathrm{~mm} /$ perhari. Jumlah penduduk kecamatan Pangalengan cukup besar. Berdasarkan data kependudukan jumlah penduduk di Kecamatan Pangalengan sebesar 148.353 jiwa dengan luas wilayah sebesar 27.294,79 ha [7]. Kepadatan penduduk yang tinggi ini dapat menimbulkan resiko yang besar apabila terjadi bencana longsor.

Hasil analisis slope morphology yang didapatkan menunjukkan bahwa daerah penelitian desa Margamukti terdiri dari kemiringan lereng yang memiliki lima klasifikasi (Gambar 3). Klasifikasipertama dan kedua yaitu sangat landai $\left(0-15^{\circ}\right)$ dan landai $\left(15^{\circ}-25^{\circ}\right)$ di daerah Kertamanah, Rancamanyar, Cipanas, Rancagede, Pangkalan, dll.

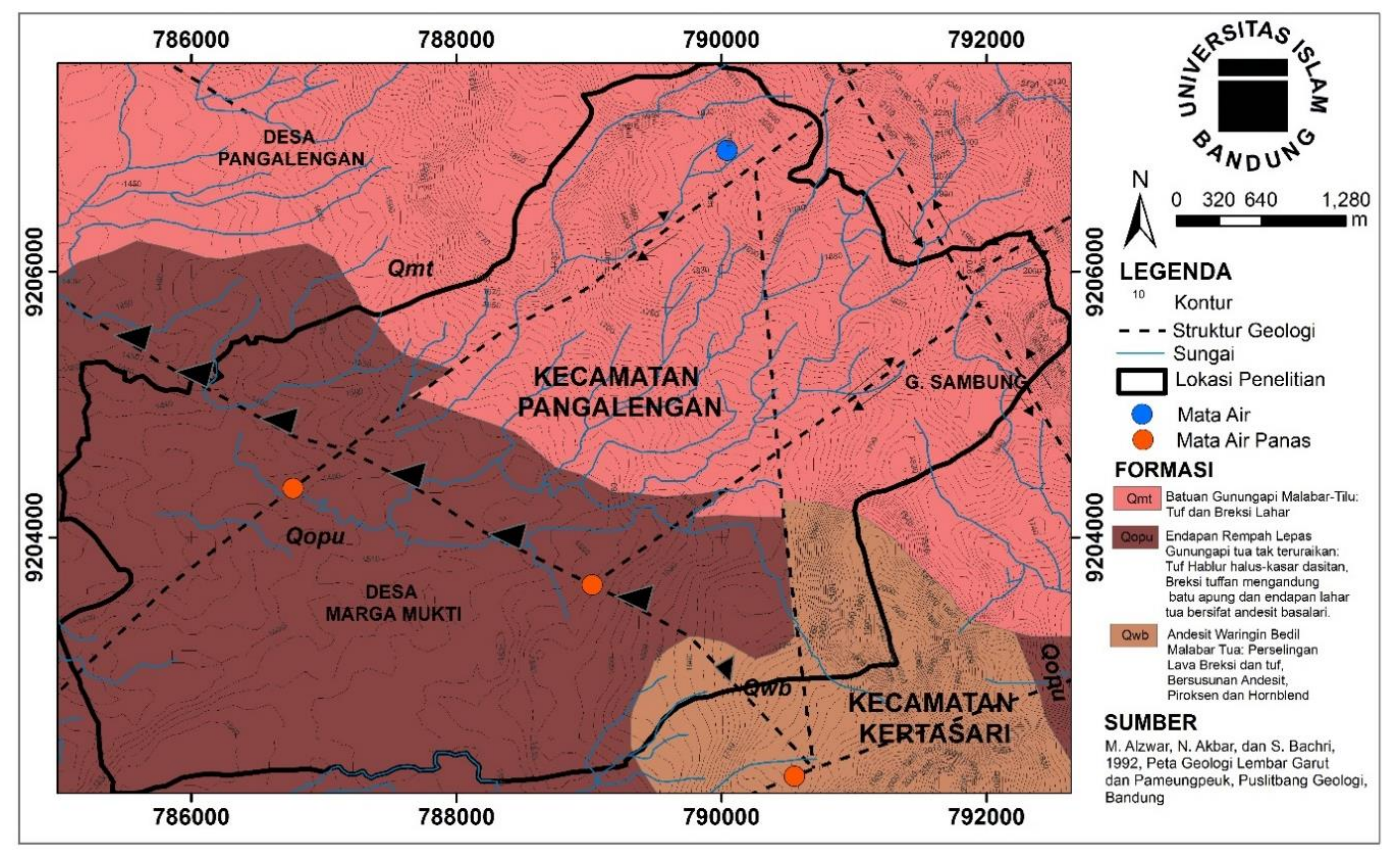

Gambar 2. Peta Litologi Desa Margamukti, Kecamatan Pangalengan, Kabupaten Bandung (dimodifikasi dari [6]). 
Klasifikasi ketiga adalah Daerah Cibeurum dengan kemiringan lerengan yang merupakan klasifikasi sedang $\left(25^{\circ}-35^{\circ}\right)$. Sementara klasifikasi keempat dan kelima adalah daerah kemiringan lereng terjal $\left(35^{\circ}-45^{\circ}\right)$ dan sangat terjal $\left(45-65^{\circ}\right)$ terdapat di daerah Cibitung dengan luas area \pm 3.038 ha menyebar ke arah selatan. Kemiringan yang sangat terjal dan terjal mengindikasikan daerah tersebut memiliki kerentanan terhadap bencana longsor. Daerah yang memiliki kemiringan yang terjal dan sangat terjal ini juga didukung dengan keberadaan sesar yang arah nya utara-selatan, sehingga daerah cibitung ini sangat rawan longsor.

Sebaran daerah rawan longsor umumnya berada pada perbukitan, yang patut diwaspadai jika daerah ini merupakan permukiman penduduk dan infrastruktur seperti jalan. Sebagai contoh kasus untuk Desa Cibitung, daerah ini merupakan permukiman penduduk dan juga terdapat infrastruktur pipa geothermal, sehingga untuk luasan daerah rawan longsor hingga \pm 3.038 ha harus diwaspadai dan segera dilakukan mitigasi. Fakta pada tahun 2015 telah membuktikan bahwa daerah ini merupakan zona rawan longsor yang menyebabkan banyak kerugian (Gambar 4).

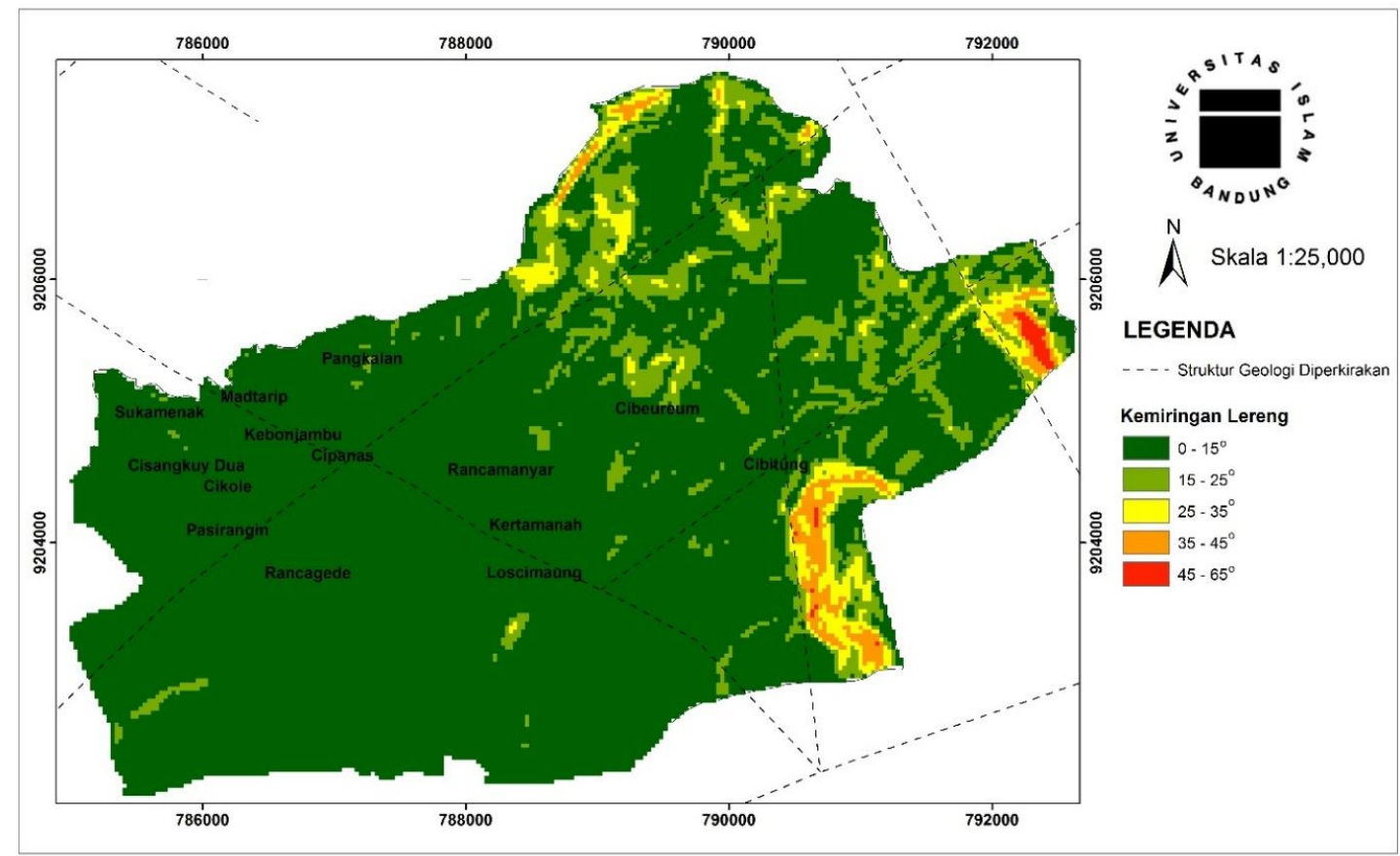

Gambar 3. Peta Slope morphology Desa Margamukti, Kecamatan Pangalengan, Kabupaten Bandung yang merupakan hasil analisis dari data Digital Elevation Model (DEM) yang didapatkan dari Aster Global DEM [8]

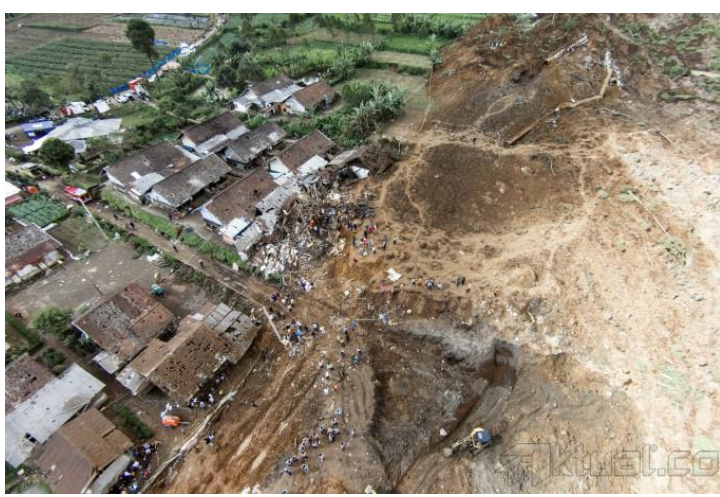

(a)

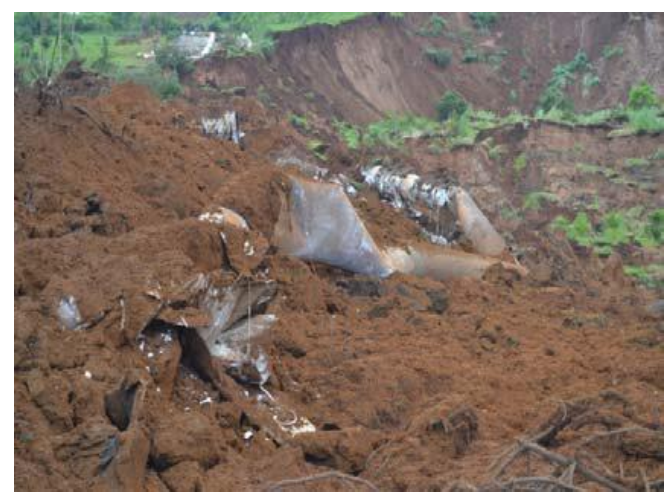

(b)

Gambar 4. Bencana longsor yang terjadi di Desa Margamukti, Kecamatan Pangalengan, Kabupaten Bandung, (a) menerangkan tentang bencana longsor yang merusak permukiman penduduk desa, (b) menerangkan tentang bencana longsor yang merusak infrastruktur pipa geothermal [9]. 


\section{Kesimpulan dan Saran}

Adapun kesimpulan yang dapat diambil dari penelitian ini adalah untuk melakukan mitigasi awal bencana longsor dapat dilakukan dengan menggunakan data Digital Elevation Model (DEM) yang didapatkan dari Aster Global DEM. Data tersebut dapat dianalisis slope morphologynya sehingga mendapatkan gambaran daerah rawan bencana longsor. Pada studi kasus Desa Margamukti ini didapatkan hasil analisis slope morphology yang terjal $\left(35^{\circ}-45^{\circ}\right)$ dan sangat terjal $\left(45^{\circ}-65^{\circ}\right)$ di daerah Cibitung, dengan luas area rawan longsor \pm 3.038 ha.

Adapun saran yang dapat disampaikan penelitian ini merupakan penelitian awal yang dapat menjadi landasan mitigasi bencana, yang selanjutnya dapat dilakukan penelitian lanjutan dengan menggunakan faktor bobot dan penambahan parameter-parameter lainnya seperti relief relatif, air permukaan, tutupan lahan, serta litologi, sehingga nantinya akan didapatkan peta zona rawan bencana longsor dengan berbagai tingkatan (low hazard zone, moderate, high, dan very high hazard zone).

\section{Ucapan Terima Kasih}

Kami ucapkan terimakasih kepada LPPM UNISBA yang telah mendanai penelitian ini dalam skema hibah dosen muda.

\section{Daftar Rujukan}

[1] BNPB (2015). Peta Bencana Tanah Longsor di Kecamatan Pangalengan, Kabupaten Bandung, Jawa Barat. Bandung: Badan Nasional Penanggulangan Bencana.

[2] S. C Shaw and D. A. Johnson (1995). Slope Morphology Model Derived from Digital Elevation Data. Northwest Arc/Info Users Conference, (pp. Oct. 23-25, 13p). Coeur d'Alene, Idaho.

[3] Bakosurtanal (1999). Peta Rupabumi Digital Indonesia Lembar 1208-631 Pangalengan. Bogor: Bakosurtanal.

[4] H. Putra (2014). Identifikasi Daerah Rawan Longsor Menggunakan Metode SMORPH-Slope Morphology di Kota Manado. Jurnal WASIAN, Vol.1 No.1, 1-7. doi:http://dx.doi.org/10.20886/jwas.v1i1.849

[5] J. Annisa, S. Sutikno, dan Rinaldi (2015), Analisis Daerah Rawan Longsor Berbasis Sisterm Informasi Geografis (Studi Kasus : Kabupaten Lima Puluh Kota, Sumatera Barat). JOM FTEKNIK, Volume 2 No. 2.

[6] M. Alzwar, N. Akbar. dan Bachri (1992). Peta Geologi Lembar Garut dan Pameungpeuk. Bandung: Puslitbang Geologi Bandung.

[7] BPS (2016). Kecamatan Pangalengan Dalam Angka Tahun 2016. Bandung: Badan Pusat Statistik Kabupaten Bandung.

[8] USGS. (2017, Januari 2). USGS Science for a changing world. Diambil kembali dari EarthExplore: https://earthexplorer.usgs.gov/

[9] I. A. Hady (2015, Agustus 04). Longsor Pangalengan. Retrieved from ESDM Dinas Energi dan Sumber Daya Mineral Provinsi Jawa Barat: www.esdm.jabarprov.go.id 
JPSE, Vol. 2, No. 1, 2017, Page 1 - 6 